\title{
Storing and sharing wisdom and traditional knowledge in the library
}

\section{Authors Information:}

Brooke M Shannon, PhD

Department of Criminal Justice \& Social Sciences

Tiffin University

United States

Jenny S Bossaller, $\mathrm{PhD}$

School of Information Science \& Learning Technologies

University of Missouri

Email: bossallerj@missouri.edu

The final, definitive version of this paper is to be published in IFLA Journal by SAGE Publications Ltd, All rights reserved. (C) Brooke M. Shannon and Jenny S. Bossaller 


\begin{abstract}
Traditional library practice focuses on print collections and developing collections of materials that have been published, which means the documents have gone through some kind of review or vetting process. This practice leaves a wide swath of potential knowledge out of the collection. For example, indigenous knowledge, beliefs, and experience are different, in that they do not undergo the same review or vetting process; we might refer to these types of content as wisdom. Non-print collections, such as collections of recorded oral histories, represent less traditional forms of knowledge. Human libraries push the boundaries further in the quest to integrate wisdom and lived experience into library collections. This paper delineates the relationship between wisdom and knowledge that arose during a phenomenological study of the everyday information practices of Kenyan university women. The women were asked to photograph everyday events from their life and describe what they saw. One finding was a divergent presentation of wisdom and knowledge. Because the women were describing this in relation to their education, we assert that this demonstrates a need to reconsider positivist assumptions in library science, bringing what the women called wisdom into the stacks. How, though, can wisdom be stored and shared?
\end{abstract}

Key words: wisdom, knowledge, oral history, living libraries, traditional knowledge 


\section{Introduction}

How can libraries store the information that its users need when that information takes a nontraditional, changeable, or living form? There are certainly many kinds of knowledge that are not textual or that fall outside of the realm of regular library collection practices. Traditional knowledge falls into this category. This paper explores possibilities of expanding limits of texts and knowledge in the library stacks.

Libraries serve to connect people to the information that they need, which might include a wide range of material such as fiction, nonfiction, or persuasive literature; "information needs" are therefore quite subjective. Librarians work within boundaries that have been established by practice and practicality formed by the types of documents that they house. Librarians are bounded by space, scope of the collection (what is available and desirable), and limitations on form (i.e., books, periodicals, audio-visual items). We can also see how 'normal library practice' is changing drastically in all of these areas, especially as digital technologies have changed space usage, limitations on knowledge, and form that the knowledge takes. These changes have come about directly and indirectly as a result of technology. For instance, reference areas have been largely reconfigured into 'commons areas' where people can meet with laptops, and the spaces of libraries have been reconfigured because of users' technology needs (Morrone and Workman, 2014; Turner, Welch, and Reynolds, 2013).

While library spaces have been reconfigured, space is certainly still very much a practical limitation. Librarians continually negotiate and reconfigure spaces in the library for the various objects and activities that they want to and are expected include in the library: periodicals, reference collections, book stacks, computer areas, and meeting spaces. The areas of a library still define its various purposes, though commons areas are designed to be much more fluid, ensuring that users have the ability to move chairs, tables, etc., according to their needs.

Several authors have explained that librarians run into limitations on which texts that they include in the library's collection. They work within established parameters of knowledge and form. Budd (2002) 
points out that knowledge "has been subjected to some kind of filtering through society's value system...has been deemed meaningful through some societally agreed-upon process” (p. 93). Radford (1992) critically explains that librarians serve as facilitators, guardians, and brokers of a modern, positivist view of knowledge; here, information is presented as a commodity. This viewpoint lays the groundwork for analyzing the limits of library collections in terms of value. We can say that library practices and research give precedence (and possibly privilege, though that might insinuate a deliberate exclusion) to texts or to graphic records that can be easily stored, understood, and analyzed for content. Collections of textual and visual documents are the physical components of 'normal library practice' (with texts being most usual). This leads us to the conclusion that normal library practice, by definition, marginalizes some kinds of information, such as communication between people - libraries do not typically organize unrecorded communication. They might organize space where communication (between books and people, between computers and people, between people and people) will occur, but they do not organize people. That falls outside of the scope of librarianship. People embody living knowledge, but are much more difficult to organize, store, and disseminate; that differentiation marks "alternative views of knowledge" that the librarian community could give serious consideration, were it not for the practical problems posed by actually carrying it out.

Another barrier to connecting the reader to the information sought is the method used by librarians to obtain books, including limitations of the publishing industry. The "normal" method for libraries to obtain texts is through publishers, jobbers, and small presses; that is how they fill the shelves. Librarians select from catalogs of books to meet the scholarly and/or recreational needs of their patrons. However, the publishing industry censors itself. Publishers publish what is publishable: that which has been vetted, is acceptable, and salable. This means that certain kinds of knowledge will make it through the publishing process, and other kinds will not. This might be considered a product of market forces, or, more ominously, censorship. For instance, Durrani (2008) writes about librarianship in Kenya during the 1980's, and distinguishes between the publications that were on the library shelves and the underground 
literature of liberation. Liberation literature was censored by the government and so was unavailable in public libraries except through what he calls "guerilla librarianship."

Information suppression is linked to discussions of Traditional Knowledge (TK), which claims that local knowledge is often superior in finding solutions to local problems. TK presents a calling for librarians to expand the information ecosphere and somehow recognize the value of wisdom and experience. A roadblock, though, is that some of that local information is not actually written down; "normal library practices" focus on texts. There is a lot of wisdom that is not found in the library stacks. Finding a way to include this into the library's collection is not only a way to connect library users to the information that they are seeking, but also an act of guerilla librarianship. It liberates knowledge and can connect users to TK.

Because librarians concentrate their efforts on developing collections of texts (or at least recorded material), it makes sense to define a text, explore textual boundaries, and identify how expanding the collection might enhance a library user's access to information. Ricoeur (1991) offers one way to think about this by describing how people interact with information in dialog or conversation. He defines text as "every utterance or set of utterances fixed by writing" (p. 135). In dialog, two people are engaged in mutual discourse; they are rooted in a present reality and have the opportunity to negotiate meanings. That exchange offers a psychological advantage that the written text cannot share. Written texts, though, offer a sociological advantage over conversation. Texts are fixed in time, can be preserved and studied. Written texts can become part of the collective memory (p. 137), but they are located in a quasi-world where reality is "intercepted" (p. 138). Similarly, traditional reading theory put the reader as recipient of knowledge (the reader as 'empty vessel'); however, more modern reading theory has put the reader in command through interpretation. Thus, reading a text might be a two-way or intersubjective experience, but Ricoeur explains that it should never be confused with speech itself (p. 146). Likewise, the reader can never leave an imprint on the text for the next reader without writing in the book, which is highly discouraged in libraries (although social tagging the catalog might be an exception worth noting). Written 
texts are only one form of communication - they are essentially one-way or limiting because the speaker (the writer) can never clarify for the reader what he is saying should there be questions (although journal clubs and written interpretations offer the reader a way to engage with the text in the presence of another). Alone, the reader has limited options for interpretation. Providing a way for the seeker of information to interact personally with the person who holds that information, then, can be seen as an important step in increasing understanding and knowledge, and helping people find what they are looking for.

\section{When is a text not a text?}

Budd (1995, p. 307) claims that "if text can be taken as a formally constructed system of signs, then many things, and certainly libraries, qualify as texts." Budd's interpretation is influenced, in part, by Brown's (1987) view of society as text, as a social structural system of speech acts, acts that can be reproduced, interpreted, and reinterpreted. Each individual has the power to analyze and act upon this text, first through interpretation and then using their own experiences to reinterpret. Turner (2012) explains that even an individual utterance can be a document. Turner refers to Frohmann (2004) who defined documents according to either "their materiality; their institutional sites; the ways in which they are socially disciplined; and their historical contingency" (p. 387); they are both socially constructed and contextual. Turner, studying institutional communication, found that oral statements should be considered documents because an utterance is "an artifact that conveys evidence" (p. 860). Thus, even utterances are something that should be of interest to documentarians and librarians.

\section{Defining knowledge and wisdom}

During the study that is described in this paper, Kenyan university women distinguished between knowledge, which they said is stored in books and libraries, and wisdom, which they associated with people, especially elders. The first objective, then, in explaining "wisdom" as an alternate path to knowledge is in establishing the relationship between knowledge and wisdom. One way to conceive of their relationship is as a hierarchy. Haeckel and Nolan (1993) have proposed a multi-level information hierarchy of variables and processes by which information becomes knowledge. Facts, at the base of the 
hierarchy, become information given a particular context. Information becomes intelligence through inference. Certitude transforms intelligence into knowledge. Finally, knowledge becomes wisdom through the process of synthesis. Arguably, the moments of distinction are just as vague as the states themselves. However, the tendency to place knowledge as antecedent to wisdom is common.

In an effort to develop an explicit theory of wisdom to explain why people are labeled wise rather than knowledgeable, intelligent, or creative, Sternberg (1990) has also found that knowledge precedes wisdom. He has not operationally defined knowledge but alludes to knowledge as, simply, what is known. In this case, knowledge is rooted in the positivist tradition and is transferable and, for example, written in books and passed along in schools. Bluck and Gluck (2005) have described wisdom as something that necessitates transmitted knowledge but also requires demonstration or possession of a wider set of what they call life-tools, such as empathy, support, self-determination and assertion. Also linking values to wisdom is Kekes (1983), who has defined wisdom as "a character-trait intimately connected with selfdirection...[and] the possession of wisdom shows itself in reliable, sound, reasonable, in a word, good, judgment" (p. 277). In other words, wisdom is the manifestation of value-mediated and reasonable judgment. Such judgment, including an understanding of differences in values and priorities, is culturally based and necessarily relies upon the mastery of various social and institutionalized norms and beliefs.

The role that experience and expertise play in wisdom has also been explored. Rowley (2009) claims that "knowledge, experience and action are key aspects of wisdom" (p. 110). Similarly, Baltes and Smith (1990) have explained wisdom as "an expert knowledge system" (p. 87), or expertise. They have defined wisdom as "a highly developed body of factual and procedural knowledge and judgment dealing with what we call the "fundamental pragmatics of life"' (p. 87).

Importantly, many studies of wisdom extend beyond educational settings. As Baltes and Smith (1990) have suggested, in studies of wisdom and intelligence, the "primary focus on school-related knowledge and skills has been questioned, and new sectors of life...have been singled out as domains within which factual and procedural forms of intelligence can be properly studied” (p. 93). Bodies of 
knowledge outside the sets of core curricula such as "the knowledge of everyday routines (e.g., knowledge of common activities and events, social norms, available human services, and social institutions)" (p. 97) come into play during the everyday pragmatics of life. Lloyd (2009) has also studied information practices beyond the academic setting, specifically in emergency response situations. She has found that written knowledge is only one source of information. Crisis responders also rely on social sources of information, such as experts in their field, and also on environmental cues.

Another aspect of wisdom is that it enables people to function in a state of uncertainty. Baltes and Smith (1990) have suggested that experts have not only knowledge of their domain but also knowledge of how to manage uncertainty, such as being aware of probabilities or the relative success or failure of relevant decisions. This tolerance of uncertainty is what Bluck and Gluck (2005) have called flexibility.

Wisdom might be conceived of as a component of tradition, or as a means to bolster traditional social systems. Wisdom is a type of learned judgment that comes from and complements the social system of which a person is part. This presents a structuralist-functional view on the purpose of wisdom; people who learn how to become a functional part of society are thought of as wise.

Howard (1994) has stressed the importance of conversation between people involved with Western development, coming in as technical experts, and the people who live in that nation's traditional society. The 'quick fixes' imposed upon the traditional society are reflection of Western knowledge system, and the process of development is imbalanced, favoring the developed nation as expert. Howard explains that "the legitimacy of the authority of the technical experts is based on the assumption of the superiority of science." Science is presented as an "objective, impersonal, rational, and universal knowledge system" (para. 7). There are many advantages to having scientist and developers who have adopt some degree of humility, and who recognize the legitimacy of local or traditional knowledge; people who know the land and understand the intricate balance of their ecology are a source of real knowledge.

\section{Western bias, colonialism, and positivism}


There are different views on the value of traditional knowledge and how it might work in modern society. Outside of science and development, education and access to information, and and laws (as representations of wisdom) demonstrate tensions that might arise.

Many librarians have noted that students from other countries do not have the same conception of the library as domestic students. Northern or Western hemisphere libraries have different traditions from Southern and Eastern hemisphere libraries. In some areas of the world, libraries are only available to scholars. The materials might be available only in the dominant language, as relics, reminders, and reinforcements of a colonial system. In the least developed areas of the world, people who hold the most power, the tribal elders, might be marked not by knowledge that is learned in books at all, but by their ability to make good judgments based on wisdom, of knowing stories, and having life experience. We might say that in the West, book knowledge is privileged over life experience. One of the relics of colonialism is the tendency to discount non-textual knowledge. We can say, therefore, that books hold more power in Western societies than they do in societies with a strong oral tradition. While we will not argue here that books are oppressive, there is a long line of thinking that books have the capacity destroy the capabilities of memory; in Western tradition, this was found in Socrates' conversations with Plato, though his second-generation student (Aristotle) wrote books and even established a library.

What are the results of establishing Western-style education, imposing a Western tradition of learning from books on non-Western societies? What might that mean for the self-determination of a nation with different values and processes of legitimation and authority? Falgout (1992) described a case of the social effects of implementing a standardized American schooling system in Pohnpei, one of four municipalities in an island nation of the Federated States of Micronesia. Rewards for completion were “primarily Western ones_-jobs, money, and manufactured goods" (p. 39). The coeducational system improved women's workforce prospects, but the new academic rites of passage also unintentionally shifted sociopolitical relations between "new elite" and the old (p. 40). The Western democratic ideal of equality upended traditional norms in both well-received and problematic ways (depending on who was 
asked and how those consequences are weighed). In this case study, the intended state of knowledge and, perhaps, wisdom (i.e., democracy) were significantly different from the actual outcome.

Similar cultural clashes occur in the United States, where similar problems or ethical questions have been raised involving Native Americans and religious people who want to remain faithful to tradition-based laws. The 1968 Indian Civil Rights Act established that United States courts have no jurisprudence in tribal decisions. One tribal practice is banishment, described by Swift (2011) as "an ancient punishment used by tribes to preserve order and rehabilitate tribal members...[which] helped maintain tribal cohesion, essential to cultural identity and protection" (p. 943). There have been appeals to U.S. courts, though, from banished members, illustrating the difficulty in maintaining a distinction between tribal and federal jurisdictions. Similarly, Wolfe (2006) has described the sovereignty of faithbased laws and religious courts' relationship with secular (i.e., U.S. and Canadian) courts. Wolfe claims that most of the time the courts have been happy to let religious courts carry out their own arbitration because self-regulation has been good for the courts. It has lightened their load, and it has been good for the people, who have been more comfortable having their disputes resolved according to their religious values. However, in-group cultural disputes might cross jurisdictions. Wolfe explains, "many cultural groups wish to preserve their distinctive cultures and resist 'state-promoted assimilation'” (p. 456). The tension occurs when state dominance interferes with religious values; however, sometimes, traditional practices violate human rights, or in-group disagreements call for state intervention.

The two disparate views of colonialism and control (or suppression) of non-Western knowledge in knowledge institutions are brought to the library discussion in Durrani (2008; 2014). Durrani describes how, in Kenya's post-Colonial society, the English established libraries and the educational system in order to maintain some modicum of control over the people. In the 1980's, activists managed to establish their own libraries for liberation purposes (Durrani, 2014); they incorporated theater and art spaces into the library as a form of engagement, and also as a method of resistance. Have people in post-Colonial nations managed to wrest control over the educational system from the oppressors now that they are in 
charge of libraries and education? Is there still a dichotomy in relation to books, education, and libraries that stands between Western culture and non-Western culture? What does globalization mean for traditional knowledge, and what do young people who live in societies that are transitioning into an interconnected, globalized society think about the difference?

This paper discusses how knowledge and wisdom were described by a group of women in Kenya, a country that has moved beyond its colonial past, but also one in which many worlds exist simultaneously. In Kenya, tribal and indigenous knowledge exists alongside schools built on Western traditions. How can these two be effectively embodied within the context of the library? The women's comments about the concepts of knowledge and wisdom prompted the question regarding the place of libraries and, ultimately, what a library is and what it does. This brings up a discussion about how knowledge and wisdom are perceived, in what context each concept is used, and how each is accessed and shared. Aside from the theoretical interest in such delineations, the findings and discussions provide credence to human libraries and other non-traditional or developing conceptualizations of the library.

\section{Methodology}

Data was gathered during a larger qualitative study about what information people describe as relevant to their everyday lives. A combination of content, phenomenological, and hermeneutical methods were used to explore Kenyan women university students' interactions with information in their everyday life. Basic content analysis was used to gain an understanding of the occurrence and co-occurrence of words. The relationship among words and how participants experienced these concepts was explored using Hycner's (1985) 15-step phenomenological method. Finally, a hermeneutic method inspired by Gadamer (2006) was used to understand the sociocultural and historical context of experiences.

The study focused on women's information practices, which is the set of institutionalized, or recurrent, information-related activities (i.e., seeking, searching, use, evaluation, production, and sharing) of a particular group or community (Savolainen, 2007). In an information practice, the unit of analysis is the individual-with-context. This can be contrasted with information behavior research in which the unit 
of analysis is the person, regardless of context. The value of this interpretive approach (compared to a more positivist approach) is that it takes into consideration information activities as they are embedded in a greater social, cultural, and historical context.

Context, in this case, is related to what knowledge is possible. In a Foucauldian sense, knowledge is more akin to a system in which claims makes sense, or not (Foucault, 1972). The organizing factor is discourse, or a certain way of knowing and the validating statements and claims that make knowing possible. Looking at the discourse makes it possible to understand how and why information activities, rather than individual behavior, are legitimized and gain value.

\section{Method}

Participants in this study included 20 women, aged 18-24, who were students at a private university in Nairobi, Kenya. Eight tribes were represented, and all but one identified as Christian.

Over the span of eight weeks, participants were asked to photograph objects they deemed relevant to their everyday life, write a description of what they intended to capture in the photograph, and then meet in a group to discuss why the object in the photograph was relevant to their everyday life.

Data included participants' spoken words during group discussion, participants' written descriptions of their photographs, and participants' collection of photographs. A total of 745 principal documents were collected, including 250 corresponding photographs, 244 written descriptions, and 251 transcribed group discussions. Only written and transcribed documents were coded for content analysis. Additional clarification was collected through face-to-face interviews, informal interactions with participants and non-participants, and through researching local events, places, and objects to which participants referred.

Importantly, participants were not asked to talk about either knowledge or wisdom, but these concepts emerged as relevant in their everyday lives. Twenty three documents, including seven photographs, eleven written descriptions, and five discussions, were collected that specifically pertained to and were coded as knowledge. Five documents, including two written descriptions and three 
discussions, explicitly addressed their conceptions of wisdom.

\section{Findings}

The students expressed a distinct difference between wisdom and knowledge. When discussing everyday life events and sources of information, participants discussed knowledge as it related to the education setting. In contrast, wisdom was related to life experience.

\section{On knowledge}

Students associated knowledge with education. Ninety-two percent of the time, knowledge was experienced in their identity role as a student and was expressed as a thing gained through going to school, going to class, and learning in class. For example, one participant explained that she was "doing classes that are teaching me about my own country which I didn't know at all. And, I'm gaining new knowledge and loving it."

Knowledge was associated with the classroom, "a place where you can gain knowledge, discover yourself, and learn new things." They spoke of school as the place where one acquires knowledge for empowerment and preparation for the future. For example, one woman said, "I believe....all the schools I've gone to have contributed to my knowledge. They might not be directly but through the education. Through wanting to gain knowledge. Through the education I have received I have managed to turn most of it into valuable knowledge that I am using in my everyday life." They said that knowledge was something that was transmitted from the institution of the school.

The library was important for the students as a place to do schoolwork and as having "all the knowledge you want." In some cases the women also associated knowledge with culture, as a result of the diversity experienced by going to the university and by integration of cultural topics into the curriculum. Books were described as "full of knowledge" or as comprising a "shelf of knowledge." Another student said that books actually "represent knowledge" and "without them you can get no 
education."

Expert knowledge was also identified. For example, people who actually worked in their field of study were described as having expert knowledge. This type of knowledge, which was similar to wisdom, was based on direct and active involvement in the topic of knowledge and had an affective (i.e., motivational, inspirational) impact.

\section{On wisdom}

In contrast, the women connected wisdom to connections with elders and religious institutions. They associated wisdom with life experience. They said that elders were wise regarding tradition, normative issues, and money because they had life experience. One student described her parents as sources of both knowledge and wisdom - saying that they are "very important sources of knowledge and information and...they're like the wisest people on earth. Even though...everyone says that we always repeat our parents' mistakes...I guess that whatever, that I kind of...learned through them so I don't have to fully repeat them." Another woman said that it is through people, not books, that she has learned the most: "you know how people say books are knowledge but I tend to believe people have more knowledge than books...There were these guys from several departments of the UN who talked about poverty and HIV...And, some of this material you don't usually get in books. You get it from the people and it has...more impact on you when you hear it from somebody else than when we read it in our books."

Another woman said that the Bible was a source of wisdom because of the stories about the people who went through difficult situations and solved problems. Of course, the Bible is a book; however, she emphasizes the personal connection to the characters in the Bible as a source of strength: "When I read it, it gives me wisdom [and new understanding] because we all need wisdom in whatever we do, in every decision we make...the Bible encourages me whenever I feel that a situation is hard for me...So many people in the Bible have gone through hard things. But, they have overcome them they have overcome them and gotten solutions to different impossible things. So, my Bible is my guiding thing, and I respect the Bible." 
Protocol or ritual played a role in sharing wisdom. For example, one woman discussed how rituals and the accompanying symbols during church service were central to gaining wisdom. The Bible, the only text-based source of information related to wisdom apart from biblical inscriptions on church walls, was integrated into church protocol, in which the vested authorities would read or lead readings from the Bible, and the house of worship was filled with various symbols of their faith.

In these cases, wisdom was contained in stories and based on people's lived experiences, while knowledge was found in books or related to education. Furthermore, knowledge was usually given; it was unidirectional. Wisdom required much more situational interpretation. Knowledge and wisdom overlapped in the domain of what can be called expert knowledge. This type of knowledge was related to the student's area of study in school, but it was different because it was based on the expert's lived experience and shared face-to-face.

The relevance of stories in wisdom is not a surprising link. For example, Pellowski (1990) explains how storytelling is universal and used as a way to entertain, transmit culture, and make sense of the world. Myths, stories, and proverbs, therefore, are embodiments or packages of shared cultural knowledge, but they might require situational interpretation. For example, in Buddhist and Hindu cultures, storytelling was used to transmit knowledge and wisdom and was even seen as superior to other forms of communication. Mbiti (1970) explains that in many African societies, philosophies are "found in the religions, proverbs, oral traditions, ethics and morals of the society concerned" (p. 2). He goes on to explain the unique value of proverbs, which are distinct from other traditions in that in that "their philosophical content is mainly situational" (p. 2). The power of myths is in their orality, in ritual retelling.

\section{Discussion}

The critical thinking skills taught in school as a part of a positivist tradition are certainly important for global participation and development, but they do not necessarily lead to situational or cultural competency. Wisdom, enacted through experience, requires flexibility for situational variability. 
Knowledge stored and shared in books and facilitated by trained professionals is an integral aspect of understanding. Knowledge stored and shared in this way can be measured, recorded, and compared for future reference. The practice of wisdom is stored in the individual and shared through time-binding but flexible containers that cannot be measured, recorded, and compared in the same way. Wisdom cannot be standardized like positivistic knowledge, but that is precisely what is lacking in the knowledge society.

Findings support the idea that wisdom is a practical approach to life that is both situational and requiring action. In this study, life experience was an indicator of wisdom. For instance, parents were referred to as wise, giving their daughter the ability to learn from their past mistakes. This confirms Rowley's (2009) claims regarding experience and action as important aspects of wisdom. However, the student also suggests that the benefits of wisdom can be passed on. Because the receiver cannot possibly relive the same experience, such an acquisition would be an intentional and reflexive activity made relevant to current situational conditions.

Knowledge and wisdom were mentioned in different contexts, suggesting an implicit divergence between the two concepts. "Wisdom" points toward everyday life rather than the school setting, confirming Baltes and Smith's (1990) suggestion that wisdom is comprised of bodies of knowledge pertinent to sectors of life other than school.

Participants did not denote a hierarchical relationship between knowledge and wisdom that would directly support the theoretical definitions given by Haeckel and Nolan (as cited in Eisenberg, Lowe, \& Spitzer, 2004) and Sternberg $(1990,2005)$. However, the findings from this small sample of indicators do not necessarily negate such a relationship.

Bluck and Gluck (2005) found that "people are perceived as wise when they have helped others to solve a problem in a way that went beyond what they had been able to see and do before" (p. 99), which was also found in this study. Age was certainly associated with wisdom. Most people who were identified as "wise" were older than the students, though one student described looking up to her little brother because of his ability to achieve goals. (She emphasized how strange that was because she was his 
elder). When people are able to meet their goals, it indicates a certain wisdom, or lifespan contextualism. While she was not speaking of wisdom in this situation, findings support Bluck and Gluck's idea that perceived wisdom might be more about age groups than just age.

One participant confirmed this when she discussed how the Bible imparted wisdom; its characters faced challenges, and she used those as lessons in her own life. She both read the Bible and listened to it, and explained that both of those experiences helped her understand the meaning of the text. She used the stories as instruction in her own life, which is an intentional and reflexive act. The text is the container of the words, but the reading and interpretation by the preacher or rector helped her understand the meaning of the text; thus, the text was embodied by the interpreter. So while learning from other people's life experience is an important aspect of wisdom, there are protocols that facilitate wisdom, especially through ritual. The ritual and the interpretation legitimizes and deepens understanding of the message. Schmit (2002) described how various ritual expressions such as gestures, repetition, rhythm, and music, in religion give legitimacy to texts, claiming that "elements of ritual are symbols that speak in ways discourse cannot" (p. 142). The idea of ritual language, beyond discourse, is that it "wholly involves us" (p. 133). In other words, interpersonal acts can be more powerful than books. In other words, this supports the knowledge - wisdom hierarchy. Information is at the lowest level, below interpersonal communication, and embodied in ritual, which leads to action (or embodied wisdom). Is it possible to facilitate this in the stacks of the library, or are libraries simply storehouses for dead words?

Brophy (2000) describes the new library as a hybrid--a shift from the traditional library of the past that housed printed matter, to a new library that facilitates learning by push technologies (pushing electronic documents to users). Recent reconceptions of the library, though, as a community center or as a learning commons, point toward yet another type of library, or another hybrid. This is the library that recognizes people as containers of knowledge or wisdom. Co-production and cross-disciplinarity have become buzzwords in academia; the lone scholar toiling away with books is no longer the norm. Likewise, group assignments are more common, and libraries have responded with more group 
workspace (Steiner \& Holley, 2009) in order to provide students with the print and online resources that they need. The library has also been reconceptualized as a place for production--of video, of writing. Another interesting manifestation of the concepts of 'library as space' is the human library, in which people are 'checked out' for library use--becoming a non-recorded human source for information (Malin, 2012). The fact that it is not recorded is a difficult hurdle for inclusion in libraries: that person is not a text.

The large university where the current study took place offers a glimpse into the difference between young women's conceptions of wisdom and knowledge, especially their view of knowledge in an education setting and the library, which houses graphic documents. Is there a way to house wisdom, as well, in the library? Hendon (2000) has explored the relationship between the storage of material objects and a community's social and moral practices. She has suggested that communities develop an "ethic of storage" that "varies in conjunction with the need to define and validate social status, reflecting how people in different kinds of society interpret social relations and enact social values" (p. 45). Essentially, storage practices "raise issues of secrecy, memory, prestige, and knowledge" and provide insight into what a society values. Storage practices might manifest in a variety of ways. For example, accumulation of certain material objects might represent status. Physical location of material objects might have social significance. An actual person might also be a container of knowledge and, in such a case, might be spatially or materially identified. Studying sources of wisdom and incorporating traditional storage values into the library's collection provides a bridge between wisdom and knowledge and creates possibilities for a richer and deeper ethic of storage. It validates a wider range of knowledge and potentially gives students a way to conceive of how other paths of knowing.

The women said that when something was written in a book, it was true. They also said, though, that things their teacher said were true. Their expression of 'truth' relates to the idea that what we know, or what we respect, is found in books - that there is a definite way of knowing that can be found 'in the stacks' through the lens of positivism. While this is not inherently problematic, their education would be 
enriched by looking toward grandparents and others who are outside of the center of these institutionalized paths to knowledge. However, such inclusion forces librarians, as well as students, to rethink authority--to expand their conception of truth, to provide academic legitimacy to that wisdom of lived experience.

\section{Implications and recommendations}

Libraries have been positioned, culturally and socially, to store and allow for potential sharing of both knowledge and wisdom. The place itself is dynamic and growing; the library is more than a place of storage, it's one for creation and community interaction. The "Library as Place" movement or the growth of academic commons within libraries is testament to this evolving role of libraries, especially on the university campus. Rethinking the role of libraries as information providers, in terms of what they provide, is compelling; it is relatively easy for libraries to collect printed materials, and convenient for students to access them. It might be more difficult for students to access people, especially elders or people who are outside of their social circle. We are often limited in our interactions to people in our various social circles, so providing access to people outside of those circles gives researchers a way to access knowledge that is not in books, and that is outside of their social circles. We can imagine that in countries that have experienced war or social upheaval or where there are strict social divisions this connection could be especially helpful in academics, from medicine and law to the social sciences.

In this section, we describe human libraries, oral history, and narrative interviews in order to reimagine how these might be incorporated into a university library setting. Human libraries show us a way to deconstruct the legitimacy of power and status manifested in static containers 'in the stacks'. The interplay between people in conversation is truly a subjective event. We do not propose to replace recorded information with human libraries, but to supplement it with voices that have not yet been recorded, to find ways to let students interact with tribal elders under the same roof (mental and physical) along with books and traditional academic sources. This gives them an opportunity to actually access wisdom, and in turn increase their understanding of why people act as they do, to understand socially 
embedded actions and reactions, and to use that wisdom to enrich their understanding of how to act in the world.

\section{Human or living libraries}

Situational knowledge or awareness is something that human libraries epitomize. They represent knowledge that is embodied in interaction rather than that which is fixed in print. This is not to imply that print is 'dead', but rather that some elements of interaction are missing when the message is mediated. Print allows people to temper or to strengthen arguments, and they are presented as a complete idea. Interaction, on the other hand, gives both sides a chance to clarify ideas and respond to questions.

The first official human library appeared in Denmark in 2000, at a Stop the Violence festival. The idea quickly spread to Hungary, Norway, Iceland, Sweden, Finland, and into the rest of Europe (The Human Library Organisation, 2012). Abergel (2005) has helped establish living libraries across Europe to help break stereotypes and sensitize people to various issues. Now, the concept is alive and thriving in North America, Australia, Asia, and South America - within libraries, on campuses (University of Missouri, 2012) and even within companies (Aaker and Hammond, 2012). The trend has recently been introduced in South Africa. In a human library, originally called a living library, the concept of a book is expanded to pertain to a human, usually a person with a particular story to tell or exemplifying a social stigma; it is a tool for combating stereotypes. A patron checks out a human book in a similar fashion to other documents. The concept has been successful in facilitating important discussion in areas with diverse populations where stereotypes and prejudices prevent cohesion and to extend the opportunity for people to interact with others with whom they may not otherwise interact.

The human library program has been especially effective in Australia, where a successful living library event at Lismore Public Library held in November of 2006 became established as a monthly event (Pearse, 2009). The Lismore Living Library was the first permanent library to be established across the globe, and the popularity and impact of the trend has led to Australia to develop a National Strategy for development of living libraries (The Human Library Organization, 2012). Lismore also has outreach 
programs such as Link Up, a program that connects students with Living Library Books in the community, and another program that brings human books to aged care facilities (Kinsley, 2009; Pearse, 2009).

In a Sydney library, the concept was introduced in response to media reports suggesting a growing sense of intolerance for diversity among the growing population (Crawshaw, 2010). The program is funded by a grant but still relies on volunteers to "act as books" and "through conversation and sharing their personal experiences...help break down prejudices and address misunderstandings" (p. 7). In Australia's Northern Territory, the human library program brings together patrons and people from other countries to discuss the issues and difficulties faced in the book's home country or as a result of moving to Australia (Hilder, 2011). The impact has helped foster harmony and community development in the territory's multicultural communities. The human library movement has been so successful in Australia that they boast more than seventy local human library organizers, which is more organizers than any of the more than thirty other countries that participate in the human library movement has (Human Library Organization, 2012).

Interacting with human texts would expose students to people who have past experiences in various aspects of life, such as a particular illness, religious background, sexual orientation, or traumatic experience. Garbutt (2008) has offered further explanation of the goal of a living library:

Whatever the differences being worked with, for example, whether multi-cultural, multi-abled, multi-sexed, multi-sexual, or multi-faith, the intended outcome is not assimilation of lesspowerful positions in society but of findings ways of coexisting in our differences. Through the practice of conversation, living library participants and organizers are seeking a form of integration that does not leave hegemonic positions undisturbed and unchanged, nor one in which all values are necessarily shared. In this sense, living libraries are 'laboratories' of multicultural cosmopolitan practice worth of greater study and research. (p. 275)

The human library movement is not a consolidated, integrated effort, and concerns and challenges 
for the program include inconsistency in cataloging or standardizing entries, the voluntary nature of human books, and possible emotional distress. Some facilitators of human libraries such as Lismore Human Library have catalogued their human books (Kinsley, 2009). In Lismore's case, the human book creates their title and the catalog description. While this preserves authenticity, the ways in which the book can be described and connected with a potential reader might also be limited. Books are also volunteers, which may arouse concerns about the type of people most likely to volunteer, longitudinal factors, and other affective factors. The Human Library Organization and Human Libraries Australia have both created resource kits to guide organizers in their efforts to recruit quality books, inspire books, and create a safe space for interaction. Interviews and meetings prior to acquiring and cataloguing a book have been recommended to discuss the book title and proposed description and, importantly, understand the book's motivation. The goal does not have to end at cultural exposure. Living libraries potentially share knowledge in multiple domains.

\section{Oral history}

Another way libraries can facilitate less mainstream exposure to wisdom is through providing a space for oral history. Kargbo (2008, p. 446), working in Sierra Leone, has suggested that librarians can provide academic validity for oral histories by selecting recordings and transcripts and then "develop directories to facilitate access to these vital data and organize and process oral traditions in a similar way they do for printed matter...for the continued existence of their cultural heritage." Oral histories have been and can be archived and stored digitally using an array of ICT, including audio and video recordings. Oral history is democratic; it's roots-up rather than top-down.

Some examples of oral history projects that might help us to conceptualize the inclusion of oral history are actually easy to find. The Library of Congress has embraced it through the Storycorps project, which is a public service that helps bring personal histories to the public (Storycorps, 2015). In 2000, the Library of Congress's American Folklife Center also started the Veterans History Project, an oral history project to make available to the public the personal accounts of American war veterans (American 
Folklife Center, 2014). These projects are important because narrative interviews can teach us what a person feels and thinks, and sets to the truth rather than a mediated version of the truth. Riessman (2012) iterates that narrative interviews have been used across many academic disciplines, from folklore to law and occupational therapy; "narrative analysis...is appropriate for studies of social movements, political change, and macrolevel phenomena" (p. 368). For the purposes of this paper, we can imagine that the interactive experience of such an interview cannot be packaged; it can be transcribed and analyzed, but each time a person is interviewed, different aspects of experience will arise based on memories that were triggered in the interaction and that particular context.

\section{Conclusion}

The students in this study identified a disjuncture in knowledge and wisdom that were wrapped in statements of value. They clearly valued both the wisdom held by elders and religious figures and also the education that they were receiving at school, but we ask if there are methods to better integrate these two domains of knowledge. This would give the students a way to bring traditional knowledge into their own studies and at the same time legitimize the values of traditional social systems in the educational setting. Integrating human libraries, storytelling, and personal interaction within the walls of the library is a way to bring wisdom into the stacks. It could be used to increase an understanding of diverse voices, especially in the postcolonial world. This will not only add to the informational ecology within the library, but also provide a means for students to integrate diverse viewpoints, including what has been identified as wisdom into their studies. 


\section{References}

Aaker D and Hammond G (2012) The human library. Marketing News 46 (11): 9.

Abergel, R (2005). Don't Judge A Book By Its Cover! The Living Library Organiser's Guide.

Budapest, Hungary: Council of Europe.

American Folklife Center (n.d.) About the Veterans History Project. Available at:

http://www.loc.gov/vets/about.html (accessed 13 March 2015).

Baltes PB and Smith J (1990) Toward a psychology of wisdom and its ontogenesis. In: Sternberg RJ

(ed) Wisdom: Its Nature, Origins, and Development. New York: Cambridge University Press, pp. $87-120$.

Bluck S and Gluck J (2005) From the inside out: People's implicit theories of wisdom. In: Sternberg R J and Jordon J (eds) A handbook of wisdom: Psychological perspectives. New York: Cambridge University Press, pp. 84-109.

Brophy P (2000) Towards a generic model of information and library services in the information age. Journal of Documentation 56(2): 161-184.

Brown RH (1987) Society As Text: Essays on Rhetoric, Reason, and Reality. Chicago: The University of Chicago.

Budd JM (1995) An epistemological foundation for library and information science. The Library Quarterly, 65(3): 295-318.

Budd JM (2002) Jesse Shera, social epistemology and praxis. Social Epistemology 16 (1): 93 - 98.

Crawshaw B (2010) Camden living library is part of community harmony strategy. inCite, $31(3)$ : 7.

Durrani S (2008) Information \& Liberation: Writings on the Politics of Information \& Librarianship. Duluth, MN: Library Juice Press.

Durrani S (2014) Progressive Librarianship: Perspectives from Kenya and Britain, 1979- 2010. London: Vita Books. 
Eisenberg M, Lowe C, and Spitzer K (2004) Information literacy: Essential skills for the information age (2nd ed.). Westport, CT: Libraries Unlimited.

Falgout, S (1992) Hierarchy vs. democracy: Two strategies for the management of knowledge in Pohnpei. Anthropology \& education quarterly 23(1): 30-43.

Frohmann B (2004) Documentation redux: prolegomenon to (another) philosophy of information. Library Trends 52(3): 387-407.

Foucault M (1972) The Archaeology of Knowledge and the Discourse on Language A.M.S. Smith, trans.

New York: Pantheon Books. (Originally published in French, 1969).

Gadamer HG (2006) Classical and philosophical hermeneutics. Theory, Culture \& Society, 23(1): $29-56$.

Garbutt RG (2008) The living library: Some theoretical approaches to a strategy for activating human rights and peace. In Garbutt R G (ed) Activating Human Rights and Peace: Universal Responsibility Conference 2008 Conference Proceedings, Byron Bay, NSW, 4 July (270-278). Lismore, NWS: Centre for Peace and Social Justice, Southern Cross University. Available at: http://epubs.scu.edu.au/cgi/viewcontent.cgi?article=1000\&context $=$ cpsj_pubs (accessed 15 March 2015).

Haeckel SH and Nolan RL (1993) The role of technology in an information age: Transforming symbols into action. In The Knowledge Economy: The Nature of Information in the 21st Century. 1993-94 Annual Review of the Institute for Information Studies, pp. 1-24. Queenstown, MD.

Hendon JA (2000) Having and holding: Storage, memory, knowledge, and social relations. American Anthropologist, 102(1): 42-53.

Hilder C (2011) Public libraries serving multicultural communities across Australia: Best practice examples. Australian Public Libraries and Information Services, 24(3): 116-124.

Howard P (1994) The confrontation of modern and traditional knowledge systems in development. 
Canadian Journal of Communication, 19(2).

Human Library Organization (2012) The history of the human library. Available at:

http://humanlibrary.org/the-history.htm (accessed 13 March 2015).

Hycner RH (1985) Some guidelines for the phenomenological analysis of interview data.

Human Studies, 8 (3): 279-303.

Indian Civil Rights Act of 1968. 25 U.S.C. § 1301-1304

Kekes, J (1983) Wisdom. American Philosophical Quarterly, 20: 277 - 232.

Kinsley L (2009) Lismore's living library: Connecting communities through conversation. Australasian Public Libraries and Information Services, 22(1): 20-25.

Kargbo JA (2008). Oral traditions and libraries. Library Review, 57(6): 442-448.

Lloyd A (2009) Informing practice: Information experiences of ambulance officers in training and on-road practice. Journal of Documentation, 65(3): 396-419.

Pearse T (2009) Living libraries Australia -A national strategy for bringing communities together. inCite, 30(11): 6 .

Malin SC (2012). What If? Exploring How Libraries Can Embody Trends of the Twenty-First Century. Young Adult Library Services, 11(1): 7 - 9.

Mbiti JS (1970) African Religions and Philosophy. New York: Praeger Publishers.

Morrone A and Workman SB (2014) Keeping pace with the rapid evolution of learning spaces. In: Frasher K (ed) The Future of Learning and Teaching in Next Generation Learning Spaces (International Perspectives on Higher Education Research, Vol. 12). Emerald Publishing Group Limited, pp. 47 - 62.

Pellowski A (1990) The World of Storytelling (Rev. ed.). Bronx, NY: H.W. Wilson.

Radford GP (1992) Positivism, Foucault, and the fantasia of the library: Conceptions of knowledge and the modern library experience. The Library Quarterly, 62(4): 408-424. DOI: 10.1086/602496 Ricœur P (1991) From Text to Action. Evanston, IL: Northwestern University Press. 
Riessman CH (2012) Analysis of Personal Narratives. In: Gubrium J et al. (eds) The SAGE Handbook of Interview Research: the complexity of the craft. Thousand Oaks, CA: SAGE Publications, pp. 367 $-380$.

Rowley J (2009) Conceptions of Wisdom, Journal of Information Science 35(1): 110 - 119.

Savolainen R (2007) Information behavior and information practice: Reviewing the "umbrella concepts" of information-seeking studies. The Library Quarterly, 77(2): 109-132. DOI: 10.1086/517840

Schmit CJ (2002) Too Deep For Words: A Theology of Liturgical Expression. Louisville, KY:

Westminster John Knox Press.

Steiner HM and Holley RP (2009) The past, present, and possibilities of commons in the academic library. The Reference Librarian 50(4): 309-332.

Sternberg RJ (Ed.) (1990) Wisdom: Its nature, origins, and development. Cambridge University Press.

Sternberg RJ and Jordon J (2005) (eds) A handbook of wisdom: Psychological perspectives. New York: Cambridge University Press.

StoryCorps (2015) About us. Available at: http://storycorps.org/about/ (accessed 13 March 2015).

Swift M (2011) Banishing Habeas Jurisdiction: Why Federal Courts Lack Jurisdiction to Hear Tribal Banishment Actions. Washington Law Review 86(4): 941 - 979.

Turner A, Welch, B and Reynolds S (2013) Learning spaces in academic libraries - A review of the evolving trends. Australian Academic \& Research Libraries, 44(4): 226-234. DOI: $10.1080 / 00048623.2013 .857383$

Turner D (2012) Oral documents in concept and in situ, part I: Grounding an exploration of orality and information behavior. Journal of Documentation, 68(6): 852-863.

University of Missouri (n.d.) MizzouDiversity. Available at: http://diversity.missouri.edu/summit/humanlibrary.php (accessed 13 March 2015).

Wolfe CL (2006). Faith-Based Arbitration: Friend or Foe - An Evaluation of Religious Arbitration Systems and their interaction with secular courts. Fordham Law Review 75: 427 - 469. 
